\title{
Effects of Shoulder Stabilization Exercise on Pain and Functional Recovery of Shoulder Impingement Syndrome Patients
}

\author{
Sang-In Park, MSc ${ }^{1)}$, Yong-Kyu Choi, MSc ${ }^{1)}$, Jung-Ho Lee, $\mathrm{MS}^{2)^{*}}$, Young-Min Kim, PhD ${ }^{3)}$ \\ 1) Department of Physical Therapy, Graduate School of Physical Therapy, Korea National University \\ of Transportation, Republic of Korea \\ 2) Department of Physical Therapy, Graduate school of Physical Therapy, Daegu University: \\ 15 Naeri-ri, Jinlyang, Gyeongsan-si, Kyeongsangbuk-do, Republic of Korea \\ 3) Department of Physical Therapy, Korea National University of Transportation, Republic of Korea
}

\begin{abstract}
Purpose] This study examined the effects of scapular stabilization exercises immediately after surgery on pain and function in patients diagnosed with shoulder impingement syndrome. [Subjects] The subjects were assigned by random sampling to an experimental group $(\mathrm{n}=15)$ to which stabilization exercise was applied and a control group $(\mathrm{n}=15)$ to which ordinary physical treatment was applied. [Methods] To evaluate the degree of pain, a $100 \mathrm{~mm}$ visual analogue scale (VAS) was used. The Constant-Murley Scale (CMS) was used to evaluate the functions of the shoulder joints. To determine the range of motion, a goniometer was used to measure range of shoulder motion. The simple shoulder test (SST) was used to determine the condition of the shoulder joints of the subjects. [Results] There were significant differences in all the items of the experimental group. The results of comparison of the therapeutic effect in the experimental and control groups revealed significant differences in active abduction, passive abduction, VAS, SST, and the CMS, except for pain. [Conclusion] The results suggest that shoulder stabilization exercise positively affects pain alleviation and functional recovery in shoulder impingement patients.

Key words: Shoulder, Impingement syndrome, Stabilization exercise
\end{abstract}

(This article was submitted Mar. 18, 2013, and was accepted Apr. 19, 2013)

\section{INTRODUCTION}

The shoulder joint has the largest range of motion in the body. Anatomically, it consists of a shallow articular fovea, which can easily cause instability between the acromion and the humeral head. Due to this instability, pain in the shoulder joints is the second most frequent type of complaint, surpassed only by lumbar pain ${ }^{1)}$.

Shoulder impingement syndrome, a shoulder joint disease, has become widely known since it was first reported by $\mathrm{Neer}^{2)}$. The underlying pathological mechanism is selfperpetuating aggravation, which results from repetitive mechanical compression of the rotator cuff muscle.

Treatment for it divided into conservative treatment and surgical treatment. Conservative treatment involves rest, medication, exercise, and electrotherapy. In early-stage impingement syndrome, conservative treatment is effective ${ }^{3)}$. In general, it is desirable to perform exercise treatment after the pain has subsided and the soft tissues have been relaxed by a warming and cooling treatment and electrotherapy.

*Corresponding author. Jung-Ho Lee (e-mail: ljhcivapt@ naver.com)

(C)2013 The Society of Physical Therapy Science

This is an open-access article distributed under the terms of the Creative Commons Attribution Non-Commercial No Derivatives (by-ncnd) License $<$ http://creativecommons.org/licenses/by-nc-nd/3.0/>.
The shoulder joint area is subject to damage because it has the largest range of motion in the body. As its stability depends on muscular activities, abnormal movement may easily change its structure ${ }^{4)}$. Stabilization exercise on a scapular plane does not place excessive force on the shoulder joints. Therefore, this type of exercise may be used safely by patients with shoulder joint damage or by patients immediately after surgery. It can be employed to correct abnormal scapular location and movement function disorders related to abnormal dynamic adjustment and to stabilize the entire shoulder girdle ${ }^{5 \text { ). }}$

Research on the effects of stabilization exercises on the stability of the scapula in shoulder impingement syndrome patients immediately after surgery is lacking. Thus, this study examined the effects of scapular stabilization exercises immediately after surgery on pain and function in patients diagnosed with shoulder impingement syndrome.

\section{SUBJECTS AND METHODS}

\section{Subjects}

The subjects were 30 patients who visited S orthopedic hospital located in Cheongju between 10 September 2012 and 12 February 2013 and were diagnosed with shoulder impingement syndrome by an orthopedist (Table 1).

They were assigned by random sampling to an experimental group $(\mathrm{n}=15)$ to which stabilization exercise was 
Table 1. General characteristics of the subjects $($ Mean \pm SD)

\begin{tabular}{lcc}
\hline & Experimental group $(\mathrm{n}=15)$ & Control group $(\mathrm{n}=15)$ \\
\hline Age $(\mathrm{yr})$ & $61.53 \pm 7.68$ & $60.93 \pm 7.04$ \\
Weight $(\mathrm{kg})$ & $58.60 \pm 7.06$ & $58.33 \pm 6.60$ \\
Height $(\mathrm{cm})$ & $158.67 \pm 8.60$ & $159.27 \pm 7.45$ \\
Period of disease $(\mathrm{m})$ & $6.73 \pm 5.19$ & $6.40 \pm 4.37$ \\
Gender (female/male) & $12 / 3$ & $11 / 4$ \\
Location of pain (left/right) & $3 / 12$ & $4 / 11$ \\
\hline
\end{tabular}

applied and a control group $(\mathrm{n}=15)$ to which ordinary physical treatment was applied. The purpose of the study was explained to the subjects, and consent to participate was obtained prior to the study.

\section{Methods}

To evaluate the degree of pain prior to and after the treatment, a $100 \mathrm{~mm}$ visual analogue scale was used.

The Constant-Murley Scale (CMS), which is a wellknown, standardized clinical evaluation method, was used to evaluate the functions of the shoulder joints. Evaluation items included the degree of pain, range of motion, activities of daily living, muscle power, and total score. It is a 100 -point scale consisting of subjective elements (35 points) and objective elements ( 65 points). The subjective elements were composed of the degree of pain (15 points) and activities of daily living (20 points), and the objective elements were comprised of the range of motion (flexion, abduction, external rotation, internal rotation; a total of 40 points) and muscle power ( 25 points); the higher each item or total score was, the better the function was considered. To determine the range of motion, a goniometer (Jamar, USA) was used to measure the passive flexion, active flexion, and extension. The simple shoulder test (12 items) was used to determine the condition of the shoulder joints of the subjects.

The control group received ordinary physical treatment to reduce pain: heat treatment for 20 minutes, ultrasound therapy for 5 minutes, laser treatment for 15 minutes, and interferential current therapy for 20 minutes. The experimental group conducted stabilization exercise after receiving the ordinary physical therapy applied to the control group.

In the scapular stabilization exercise, the subjects lay on their sides with the nonparetic side on a treatment table. The elbow joint and the shoulder joint of the paretic side were bent at $90^{\circ}$, and the hands were placed on the treatment table. The therapist placed a slight weight on the upper extremity of the paretic side and directly applied resistance against elevation, depression, and retraction on the scapula of the subjects and applied resistance against protraction on the subjects' olecranon fossa. The therapist applied smooth resistance to the subjects.

In the stabilization exercise for the shoulder joints, the subjects were placed in a standing position with both hands pressed against the wall and the shoulder joints bent at $90^{\circ}$. At this point, the therapist applied alternative resistance to the shoulder and the trunk, and the subjects were instructed to maintain their position against such resistance.
In all the exercises, the subjects maintained the position for 10 seconds, and they took a rest for 3 seconds. Ten repetitions was considered one set, and the subjects conducted three sets. A break of 3 minutes was given between each set. In stabilization of the scapula and shoulder joint, the therapist alternatively applied resistance in different directions to the subjects. The treatment was applied three times per week, for four weeks, for a total of 12 times.

In the data processing, descriptive statistics were used to detect general characteristics of the subjects. A paired t-test was employed to examine differences in pain alleviation and functional improvement of the experimental group and the control group before and after the treatment. For the data analysis, SPSS (version 12.0) for Windows was used, and the significance level was set at $\alpha=0.05$.

\section{RESULTS}

There were significant differences in active flexion, active abduction, and passive flexion, and passive abduction in the experimental group $(\mathrm{p}<0.05)$, and there were significant differences in all the items of the visual analogue scale, simple shoulder test, and CMS $(\mathrm{p}<0.05)$ (Table 2). There were significant differences in active flexion, passive flexion, active abduction, and passive abduction in the control group $(\mathrm{p}<0.05)$; VAS and SST did not show a significant difference; and CMS showed a significant difference in ADL, ROM, and power but not in pain $(\mathrm{p}<0.05)$ (Table 3$)$. In addition, the results of comparison of the therapeutic effect in the experimental and control groups revealed significant differences in active abduction, passive abduction, VAS, SST, and all components of the CMS (ADL, ROM, and power) except for pain (Table 4).

\section{DISCUSSION}

This study examined the effects of shoulder stabilization exercise on pain alleviation and functional recovery of shoulder impingement syndrome patients immediately after surgery. Shoulder pain is a very common musculoskeletal disease with a high incidence rate (about 7 to $36 \%$ ). It affects about $20 \%$ of the entire adult population ${ }^{6}$. The incidence rate of such shoulder pain is known to increase with age and is highest in those around 50 years old ${ }^{7}$. Twentyeight percent of shoulder damage needs medical treatment, such as orthopedic intervention ${ }^{8)}$.

Functional disorder of the shoulders or shoulder pain greatly affects the performance of essential activities of 
Table 2. Comparative analysis of the experimental group before and after the treatment (Mean \pm SD)

\begin{tabular}{|c|c|c|c|}
\hline \multicolumn{2}{|c|}{ 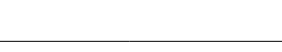 } & Before $(n=15)$ & After $(n=15)$ \\
\hline \multicolumn{2}{|c|}{ Active flexion* } & $77.67 \pm 12.08$ & $86.33 \pm 13.15$ \\
\hline \multicolumn{2}{|c|}{ Active abduction* } & $74.00 \pm 5.73$ & $82.67 \pm 7.03$ \\
\hline \multicolumn{2}{|c|}{ Passive flexion* } & $96.42 \pm 9.03$ & $105.45 \pm 13.12$ \\
\hline \multicolumn{2}{|c|}{ Passive abduction } & $89.67 \pm 7.89$ & $97.67 \pm 7.76$ \\
\hline \multicolumn{2}{|c|}{ Visual analog scale* } & $56.67 \pm 12.34$ & $44.67 \pm 14.07$ \\
\hline \multicolumn{2}{|c|}{ Simple shoulder test* } & $10.87 \pm 1.55$ & $9.33 \pm 1.87$ \\
\hline \multirow{5}{*}{ CMS } & Pain* & $6.67 \pm 2.44$ & $9.33 \pm 1.75$ \\
\hline & $\mathrm{ADL}^{*}$ & $11.33 \pm 1.44$ & $14.53 \pm 2.56$ \\
\hline & $\mathrm{ROM}^{*}$ & $17.33 \pm 5.58$ & $22.27 \pm 5.44$ \\
\hline & Power* & $13.47 \pm 2.80$ & $18.33 \pm 2.44$ \\
\hline & Total* & $48.80 \pm 10.26$ & $66.60 \pm 8.13$ \\
\hline
\end{tabular}

$* \mathrm{p}<0.05, \mathrm{CMS}=$ Constant-Murley scale, $\mathrm{ADL}=$ activities of daily living, $\mathrm{ROM}=$ range of motion

Table 4. Comparative analysis between the groups (Mean \pm SD)

\begin{tabular}{|c|c|c|c|}
\hline & & $\begin{array}{l}\text { Experimental } \\
\text { group }(n=15)\end{array}$ & $\begin{array}{l}\text { Control group } \\
(\mathrm{n}=15)\end{array}$ \\
\hline \multicolumn{2}{|c|}{ Active flexion } & $-8.67 \pm 3.99$ & $-8.33 \pm 3.62$ \\
\hline \multicolumn{2}{|c|}{ Active abduction* } & $-8.33 \pm 3.56$ & $-3.36 \pm 2.89$ \\
\hline \multicolumn{2}{|c|}{ Passive flexion } & $-9.67 \pm 4.67$ & $-8.91 \pm 3.09$ \\
\hline \multicolumn{2}{|c|}{ Passive abduction* } & $-8.14 \pm 2.97$ & $-3.43 \pm 2.98$ \\
\hline \multicolumn{2}{|c|}{ Visual analog scale* } & $12.46 \pm 7.12$ & $4.67 \pm 7.04$ \\
\hline \multicolumn{2}{|c|}{ Simple shoulder test* } & $1.53 \pm 1.06$ & $0.33 \pm 1.18$ \\
\hline \multirow{5}{*}{ CMS } & Pain & $-2.67 \pm 2.58$ & $-1.02 \pm 2.38$ \\
\hline & $\mathrm{ADL}^{*}$ & $-3.20 \pm 1.81$ & $-1.20 \pm 1.47$ \\
\hline & $\mathrm{ROM}^{*}$ & $-4.93 \pm 1.13$ & $-2.13 \pm 1.59$ \\
\hline & Power* & $-4.87 \pm 1.05$ & $-1.54 \pm 0.85$ \\
\hline & Total* & $-17.80 \pm 4.79$ & $-6.64 \pm 4.81$ \\
\hline
\end{tabular}

${ }^{*} \mathrm{p}<0.05, \mathrm{CMS}=$ Constant-Murley scale, $\mathrm{ADL}=$ activities of daily living, $\mathrm{ROM}=$ range of motion

daily living, degrades the quality of life, and may lead to severe disorders, thereby making it impossible to work for extended periods ${ }^{9}$.

Medical conditions that trigger shoulder pain include adhesive capsulitis, impingement syndrome, myofascial pain syndrome, hemiplegic shoulder pain, glenohumeral instability, glenohumeral joint arthritis, and biceps tenosynovitis. Among these, shoulder impingement syndrome has been reported as a very frequent causative factor in shoulder pain ${ }^{10)}$.

Symptoms of shoulder impingement syndrome include pain and edema of the shoulder joints and restriction in anterior flexion, internal rotation, and abduction. In the early stage of the disease, patients feel pain in the shoulder joints when raising the hands outward or forward, and most have difficulty sleeping due to pain ${ }^{11)}$. As the symptoms progress, instability and discomfort of the shoulder joint occur, and stiffness of the joints increases.

In terms of treatment, functional motions should be watched from overall appearance, and separate evaluation
Table 3. Comparative analysis of the control group before and after the treatment $($ Mean \pm SD)

\begin{tabular}{|c|c|c|c|}
\hline & Before $(n=15)$ & After $(n=15)$ \\
\hline \multicolumn{2}{|c|}{ Active flexion* } & $77.00 \pm 13.862$ & $85.33 \pm 15.407$ \\
\hline \multicolumn{2}{|c|}{ Active abduction* } & $75.46 \pm 9.220$ & $80.33 \pm 9.976$ \\
\hline \multicolumn{2}{|c|}{ Passive flexion* } & $97.33 \pm 15.999$ & $101.67 \pm 15.999$ \\
\hline \multicolumn{2}{|c|}{ Passive abduction* } & $89.67 \pm 15.976$ & $93.33 \pm 16.330$ \\
\hline \multicolumn{2}{|c|}{ Visual analog scale } & $63.67 \pm 13.819$ & $60.67 \pm 15.976$ \\
\hline \multicolumn{2}{|c|}{ Simple shoulder test } & $10.33 \pm 1.291$ & $10.00 \pm 1.464$ \\
\hline \multirow{5}{*}{ CMS } & Pain & $7.33 \pm 3.716$ & $8.33 \pm 3.086$ \\
\hline & ADL* & $12.13 \pm 2.326$ & $13.33 \pm 2.350$ \\
\hline & $\mathrm{ROM}^{*}$ & $19.73 \pm 4.832$ & $21.87 \pm 5.208$ \\
\hline & Power* & $14.80 \pm 3.256$ & $15.80 \pm 3.212$ \\
\hline & Total* & $53.33 \pm 8.926$ & $59.33 \pm 9.969$ \\
\hline
\end{tabular}

$* \mathrm{p}<0.05, \mathrm{CMS}=$ Constant-Murley scale, $\mathrm{ADL}=$ activities of daily living, $\mathrm{ROM}=$ range of motion

of the shoulder joint motions is meaningless. Adjustments of the scapula and movements of the shoulder joints are interdependent. Therefore, when a person tries to move the upper extremities and the range of motion is decreased, the joints and soft tissues are damaged. So the treatment needs to consider the arrangement and movement of the scapula and the humerus. Moreover, imbalance and pain in the shoulder girdle muscle can trigger inappropriate postural changes, such as a static fixed posture ${ }^{12}$. Preventive aspects for problems may occur in the future, and muscular imbalance should be considered. Stability should be obtained first to ensure that the scapula and the shoulder joints are equipped with the capabilities to respond effectively to the movement of the scapula and the shoulder joints. The second step should focus on external rotation, flexion, and abduction. The third step should address aspects of adduction, extension, and internal rotation, in that order.

Magee $^{13)}$ defined stabilization as a person's ability to consciously and unconsciously adjust large and minute movements of the joints and noted that the shoulder joints had the largest range of motion in the human body. As these are unstable, this study also noted that the role of muscles is important in dynamic stability and that normal movement patterns of the shoulder joints are accompanied by stabilization rhythms of the scapula.

Scapular stabilization exercise is used to correct abnormal scapular location and functional movement disorder and primarily provides stability to the entire scapula ${ }^{5)}$. For stability of the shoulder joints, balanced development of the shoulder joint complex is important, but stability of the scapulothoracic joints rather than the glenohumeral joints should be provided first. The scapulothoracic joint is an imaginary joint consisting of soft tissue mobilization planes comprising the shoulder joint area. The function of the scapulothoracic joint is essential for mobility and stability of the upper extremities.

As stabilization exercise of the scapular plane does not place excessive force on the shoulder joints, it can be safely applied to patients with shoulder joint damage immediately after surgery. The current trend in rehabilitation exercise 
for low back pain patients is to focus primarily on the internal stability of the lumbar spine ${ }^{14)}$.

An approach to motor damage of the shoulder joint should be made after the scapula is normally adjusted by stabilization of the scapula. Any functional disorder in the shoulder joint should be approached together with treatment by external rotation motions. Both abduction and flexion motions depend on external rotation. Therefore, if conditions for precise external rotations (ideal joint arrangement and muscle contraction capabilities) are not present, it is difficult to expect painless motions. Thus, stability of the scapula in functional movement disorders of the scapula should be obtained first, and this should be followed by external rotation, flexion, abduction, adduction, extension, and internal rotation exercises ${ }^{15}$.

In the present study, active flexion, active abduction, passive flexion, and passive abduction were significantly increased $(\mathrm{p}<0.05)$ in the experimental group. This result is consistent with the findings of a study by Jung et al. ${ }^{16)}$, who examined the effects of scapular plane stabilization exercise on upper extremity muscle strength. The significant increase in active flexion and abduction is attributed to correction by the stabilization exercise of the abnormal location of the scapula and functional movement disorder related to abnormal dynamic adjustment.

In the group with shoulder impingement syndrome who participated in stabilization exercise immediately after surgery, there was a significant difference in pain, activities of daily living, and muscle strength and an improvement in flexion and abduction, although the latter was not significant. The primary problem with the scapula is inappropriate scapula movement and downward rotation. Downward rotation, protraction, abduction, and elevation trigger shortening of the upper trapezius and the levator scapulae due to their excessive action and the weakening of the lower trapezius and the serratus anterior ${ }^{17)}$. In addition, this triggers approach of the humeral head to the acromion, and flexion and abduction of the shoulder joints is restricted; this results in abnormal arm elevation and impingement syndrome. Elevation of the shoulder joint becomes more difficult due to shortening of the pectoralis major muscle and the pectoralis minor muscle ${ }^{18)}$.

Obviously, external rotation of the shoulder joints is necessary for free movement of the supraspinatus muscle and tendon when subjects stretch or raise their arms. In particular, external rotation of the shoulder joints aids vertical displacement in the subacromial space. Without this motion, the humeral head crushes the mucous cyst and the supraspinatus muscle tendon within the subacromial space due to a lack of vertical displacement of the humeral head, triggering chronic pain and leading to functional restriction ${ }^{19}$.

In the evaluation in the present study using the CMS, there were significant differences in all items between the experimental group and the control group $(p<0.05)$. This result is consistent with that reported in the study by Jung et al. ${ }^{16)}$, who examined the effects of stabilization exercise on the range of motion and pain. Their findings were attributed to the scapular stabilization exercise preventing inappropriate contraction of the muscles, adjusting the movement, and aiding proper posture. In this study, the use of stabilization exercise to treat shoulder impingement syndrome in patients reduced their pain and had positive effects on their functional recovery. However, this study had some limitations, namely, a short study period and a small number of subjects. More efficient and systematic research to shed light on the role of stabilization exercise is needed.

\section{REFERENCES}

1) Berg EE: The shoulder a structure of subtlety. J South Orthop Assoc, 1995, 4: 167-168. [Medline]

2) Neer CS: Anterior acromioplasty for the chronic impingement syndrome in the shoulder. J Bone Joint Surg Am, 1972, 54: 41-50. [Medline]

3) Park JY, Kim MH: Changes of ranges of motion according to ages and manifestation frequency of impingement sign in shoulder impingement syndrome. J Korean Orthop Assoc, 1997, 32: 384-390.

4) Lippitt S, Masten F: Mechanisms of glenohumeral joint stability. Clin Orthop Relat Res, 1993, 291: 20-28. [Medline]

5) Mottram SL: Dynamic stability of the Scapula. Man Ther, 1997, 2: 123 131. [Medline] [CrossRef]

6) Green S, Buchbinder R, Glazier R, et al.: Systematic review of randomised controlled trials of interventions for painful shoulder: selection criteria outcome assessment and efficacy. BMJ, 1998, 316: 354-360. [Medline] [CrossRef]

7) Linsell L, Dawson J, Zondervan K, et al.: Prevalence and incidence of adults consulting for shoulder conditions in UK primary care: patterns of diagnosis and referral. Rheumatology (Oxford), 2006, 45: 215-221. [Medline] [CrossRef]

8) Peters D, Davies P, Pietroni P: Musculoskeletal clinic in general practice: study of one year's referrals. Br J Gen Pract, 1994, 44: 25-29. [Medline]

9) Smith KL, Harryman I, Douglas T, et al.: A prospective, multipractice study of shoulder function and health status in patients with documented rotator cuff tears. J Shoulder Elbow Surg, 2000, 9: 395-402. [Medline] [CrossRef]

10) Ostör AJ, Richards CA, Prevost AT, et al.: Diagnosis and relation to general health of shoulder disorders presenting to primary care. Rheumatology (Oxford), 2005, 44: 800-805. [Medline] [CrossRef]

11) Kim IS: Review of shoulder joint impingement syndrome. Korean Acad Clin Electrophysiol, 2004, 2: 93-100.

12) Murphy DR: Conservative Management of Cervical Spine Syndromes. USA: McGraw-Hill Medical, 2000, pp 60-64.

13) Magee DJ: Instability and Stabilization. Theory and Treatment, 1999.

14) Rasmussen-Barr E, Nilsson-Wikmar L, Arvidsson I: Stabilizing training compared with manual treatment in sub-acute and chronic low-back pain. Man Ther, 2003, 8: 233-241. [Medline] [CrossRef]

15) Jang JH, Kim SY, Koo BO: Serratus anterior muscle exercise for the winging scapula: case study. J Korean Acad Orthopecic Man Ther, 2003, 12: 69-77.

16) Jung YW, Bae SS, Jang WS: The effect of neural mobilization on the grip strength. Korean Soc Phys Med, 2007, 2: 11-20.

17) Janda V, Frank C, Liebenson C: Evaluation of Muscular Imbalance. In: Rehabilitation of the Spine: A Practitioner's Manual. Philadelphia: Lippincott Williams \& Wilkins, 1996, pp 97-112.

18) Sahrmann S. Diagnosis and Treatment of Movement Impairment Syndromes. Mosby, 1998, 200: 193-261.

19) Dromerick AW, Edwards DF, Kumar A: Hemiplegic shoulder pain syndrome: frequency and characteristics during inpatient stroke rehabilitation. Arch Phys Med Rehabil, 2008, 89: 1589-1593. [Medline] [CrossRef] 